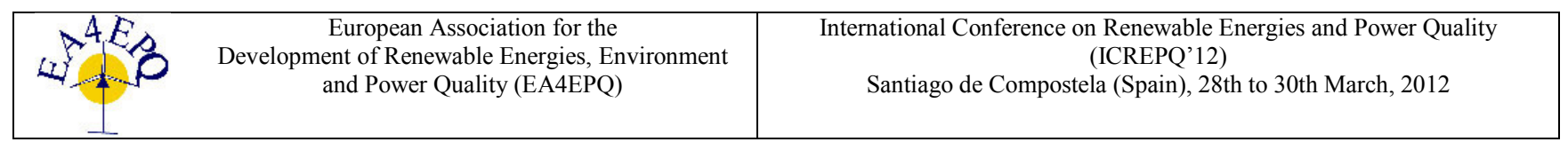

\title{
Modelling and Validation of the Magnetizing Curve to Represent Saturated Core Reactor Using ATP Simulator
}

\author{
J.A.F. Barbosa Jr, J. C. Oliveira, T. V. Silva, I. N. Gondim, F. P. Santilio and L. N. Velasco \\ Faculty of Electrical Engineering \\ UFU, Federal University of Uberlandia \\ Campus Santa Monica - Av. Joao Naves de Avila, 2121- Bloco 3N - Uberlandia (Brazil) \\ Phone/Fax number:+55 34 32394733/+55 34 32394704, e-mail: johnareis@gmail.com, jcoliveira@ufu.br, \\ tvsilva@gmail.com, gondim.isaque@gmail.com, fabricio.qee@gmail.com, loana.velasco@gmail.com
}

\begin{abstract}
This paper is focused on the proposal and validation of a procedure to obtain the necessary data to model the magnetization curve of saturated core reactors as required for the voltage regulator device constituted by a parallel combination of an inductive saturated unit and a fixed capacitor bank. The methodology to model the nonlinear device is based on constructive parameters and information associated to the type of magnetic material utilized to build up the equipment. The results are expressed in terms of the relationship between the core flux and current values which are used to feed the ATPDraw time domain simulator. Computational studies are then carried out to find the reactive power absorbed by the reactor as a function of the applied voltage, and the theoretical results are compared to three prototypes having different ratings. The experimental results derived from $7 \mathrm{kVAr}-0.22 \mathrm{kV}$, $600 \mathrm{kVAr}-13.8 \mathrm{kV}$ and $3 \mathrm{MVAr}-34.5 \mathrm{kV}$ products are then utilized to validate the saturation curve ATP representation through a comparative performance analysis of the absorbed reactive power with the voltage variation.
\end{abstract}

\section{Key words}

Saturated Reactor; Magnetization Curve; Voltage Regulation; Harmonic Distortion; ATP Simulator.

\section{Introduction}

The power systems must be designed and operated so as to provide supply voltage levels within acceptable limits. When the violation of these values occurs, several known commercial solutions can be used to mitigate the problem. Among the traditional equipment used since the beginning of power system operation, two principles for the voltage compensation have been utilized. One is based on the reactive power consumption or injection, and the other, by voltage regulation procedures using tap changers or voltage reinforcement. As for the reactive power approach, the most common solutions are based on fixed or automatic capacitor banks and the classical synchronous compensators. In the same direction, around the 1980's, the development of power electronic components allowed for more modern compensation devices such as: thyristor controlled reactors (TCR), thyristor switched capacitors (TSC), and more recently the unified power flow controllers (UPFC), based on PWM converter units [1]. The choice between one of other strategy should be based on the evaluation of technical and economic issues. Focusing on these concerns remerges the idea of using an old technology widely used in the 1960's. The equipment in mind is the static reactive compensator which makes use of a combination of a saturated electromagnetic device in parallel to a fixed capacitor bank to provide a dynamic and quite rapid time response voltage control [2], [3]. This alternative here referred to as Saturated VAr Compensator (SVC) [4] [10], has the following attractive properties: construction and operational simplicity, low maintenance, and competitive cost. Due to well-known past experience, it must be stressed the recognition of some drawbacks related to this technology. Thus, it is not intended to state that this type of compensator would emerge as a competitive strategy to the power electronic ones, but whenever the application requires low maintenance needs, no special installation, robustness, lower cost, rapid response, and does not have strict environment and harmonic injection concerns, the use of the discussed arrangement may emerge as a suitable solution.

Focusing on the saturated reactor itself, it is noteworthy that its main properties have a close relationship with the magnetic material or its $\mathrm{BxH}$ curve. Therefore, a correct representation of the non-linearity involving this component plays a very important role in the compensation process. Although a good knowledge has been achieved in relation to reactor modeling in the ATPDraw software [11], there are still some issues that need further investigation to improve the overall equipment representation. This is the case of the SVC magnetization curve due to the fact that the reactive power consumption as a function of the applied voltage will be strongly dependent on this relationship.

Within the above context, this paper is concentrated on the establishment of a procedure to obtain the necessary information about the magnetization curve for a given reactor as a function of constructive parameters and the type of magnetic material utilized to build up the unit. By 
using the relationship between the core flux and current for a specific reactor, computational studies are, then, performed to obtain the equipment reactive power as a function of the supplied voltage. This is repeated in three different built up reactors prototypes: a $7 \mathrm{KVAr}-0.22 \mathrm{kV}$, a $600 \mathrm{kVAr}-13.8 \mathrm{kV}$ and a $3 \mathrm{MVAr}-34.5 \mathrm{kV}$. The individual dependence between the absorbed reactive power with the voltage, derived from the computational investigations are then compared to laboratory results so as to validate the overall procedure to define the required magnetization curve.

\section{Static Compensator Type Saturated Reactor: Basic Arrangement}

The basic constitution of a static compensator with saturated core reactor can be observed in Fig. 1. This consists of a saturated core reactor and two capacitors banks: one connected in parallel and the other in series (optional) with the reactor. This topology requires that the reactive power injected or absorbed by the equipment be depend on the conditions imposed by the voltage busbar whereby the equipment is connected. More details about the compensator as well as on the elements that constitute the device can be found in [3]-[10].

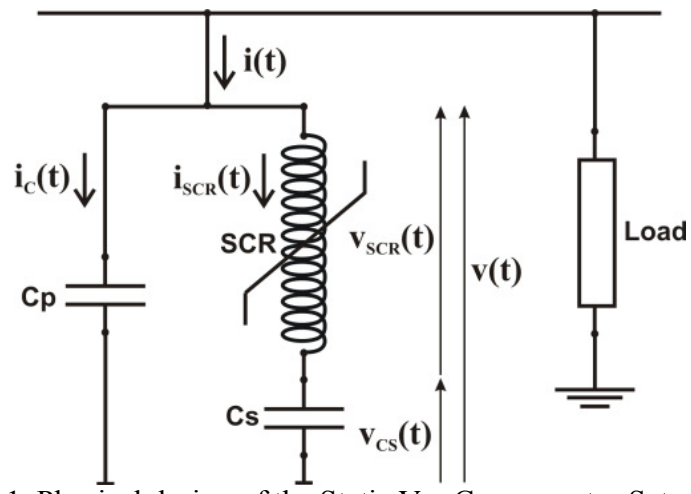

Fig. 1. Physical design of the Static Var Compensator Saturated Core Reactor (SVC-SCR).

The capacitor banks comprising the compensator are linear elements while the SCR is responsible for the nonlinear characteristic of it. Taking into account only the nonlinear behavior of the saturated reactor, the relationship between the applied voltage, and the current drawn by the inductive component, i.e., its voltage versus current $(\mathrm{VxI})$ characteristic will show the shape illustrated in Fig. 2. In this, it can observe that, for lower voltage conditions, the current absorbed by SCR is small because the SCR is lead to its non-saturated region. On the other hand, if the voltage increases above the so called curve knee, the SCR reaches the saturation region and goes to the reactive current absorbing stage in accordance with the equipment design. The characteristic curve (VxI) shows that the voltage regulation provided by this device will be, clearly, directly influenced by the nonlinearity of the curve $(\mathrm{BxH})$ of magnetic material used in the construction of the reactor core.

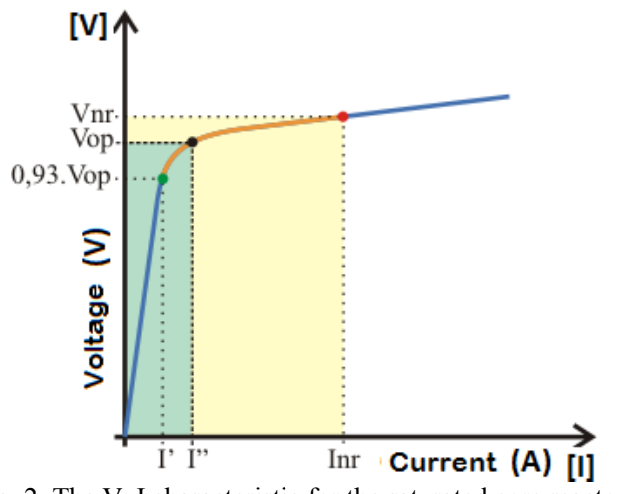

Fig. 2. The VxI characteristic for the saturated core reactor.

This nonlinear behavior of SCR implies the generation of harmonic current components. This has oriented researchers to seek for special winding arrangements in order to achieve an internal compensation of these high frequency currents. This aim was achieved through topologies known as twin-tripler (six columns magnetic) and treble-tripler (nine columns magnetic) [3]. Fig. 3 illustrates the composition of the first constructive arrangement, and, using this philosophy, only the harmonic orders defined by the expression $n=12 k \pm 1$ are produced, where $\mathrm{k}$ is an integer number. As a matter of fact, this is equivalent to the classical 12 pulse rectifiers that produces only 11, 13, 23, 24, and others corresponding components.

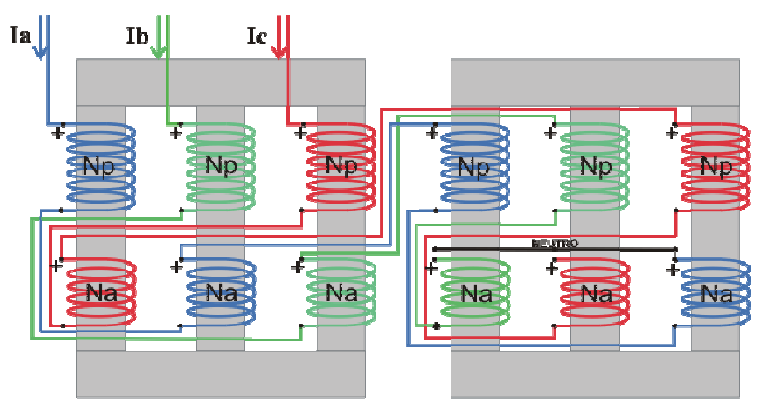

Fig. 3. The twin-tripler constructive arrangement for the saturated reactor.

\section{Saturated Core Reactor Magnetizing Curve Representation}

Fig. 4 shows the block diagram representing the steps to be fulfilled towards the process for the determination of the magnetization curve (concatenated flux versus current or $\lambda \mathrm{x}$ I relationship) as required by the ATP simulator.

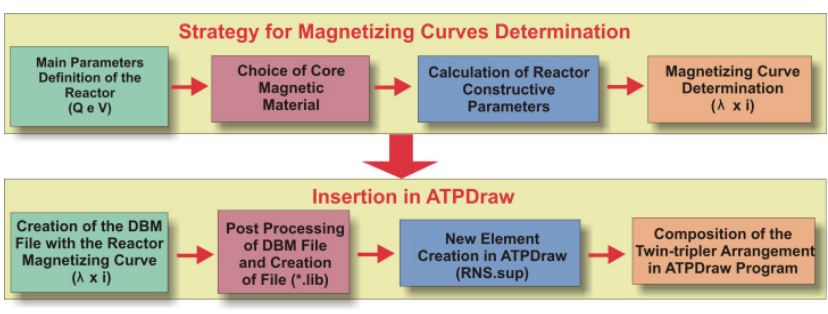

Fig. 4. The procedure to model the satured core reactor magnetization curve in the ATP simulator.

The characteristic of the magnetization curve of the saturated reactor depends basically on the type of electromagnetic material used to construct the core of the 
equipment. Among the commercial magnetic materials most used for these purposes arises the silicon steel sheets-grain oriented, non-oriented, and the blades of amorphous materials. The use of the last one contributes to the reduction of losses in core, but the most common type of core is the first one. Thus, following the availability of the materials utilized by the transformer manufacturers, the chosen type of material here defined is the silicon-steel sheet of $0.3 \mathrm{~mm}$. This corresponds to the magnetization curve $(\mathrm{BxH})$ given in Fig. 5, and this is the relationship to be applied for this paper purposes.

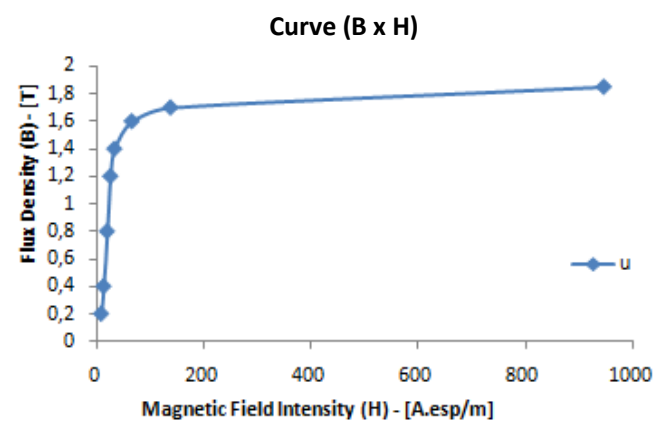

Fig. 5. Silicon steel $0.3 \mathrm{~mm} \mathrm{BxH} \mathrm{commercial} \mathrm{sheet.}$

Through of the electrical and geometrical information of saturated core reactor, calculated in accordance with the guidelines and the reactor design classical approaches, such as given in [12] and others, it is possible to correlate the flux density in terms of flux per turn of winding and the magnetic field in terms of current. This follows well known equations, which are given by expressions (1) and (2). At the end, the above data sheet will provide the required relationship $(\lambda \times \mathrm{i})$.

$$
\begin{array}{cc}
\lambda=\mathrm{N}_{\mathrm{p}} \cdot \Phi & \text { [Wb.turn] } \\
\mathrm{i}=\frac{\mathrm{H} . \mathrm{l}}{\mathrm{N}_{\mathrm{p}}} & {[\mathrm{a}]}
\end{array}
$$

Being:

$\mathrm{Np}$ - Number of turns of the winding;

$\Phi-$ Flux per turn of the winding [Wb];

$\mathrm{H}$ - Magnetic field intensity [A.turn/m];

1 - Height of the primary coil winding $[\mathrm{m}]$;

Once the above relationship is obtained, in point by point form or either in mathematical terms, its insertion in the software is then made. In order to accomplish that, a special card, type Data Base Module (DBM), has been created to provide means to the inclusion of the above nonlinearity representation in the ATP. This has produced a new card named (*.lib). The archive thus obtained constitutes the basis of the component (SCR.sup) now available by the ATPDraw. Nevertheless such facility, it must be stressed that this component is intended to represent one of the magnetic columns of the reactor with its respective windings. Fig. 6 illustrates the card (*.lib) here discussed and highlights the magnetization curve implemented.

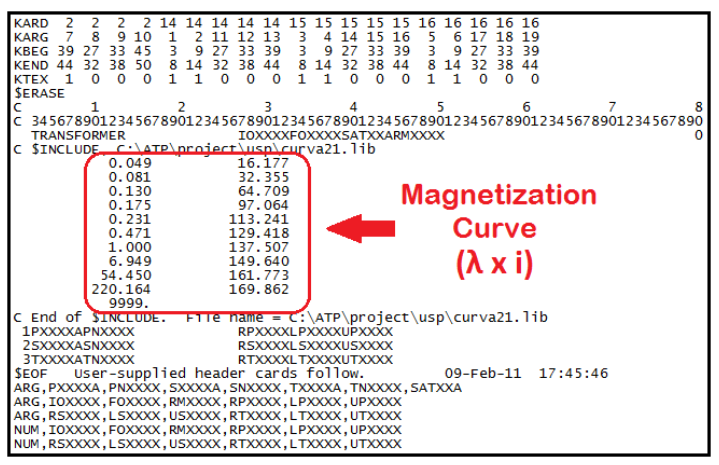

Fig. 6. Card (*.lib) representing a column of the SCR with its magnetization curve $(\lambda \times$ i).

On the other hand, Fig. 7 (a) illustrates the developed component (SCR.sup) to the ATPDraw interface through the use of the routine New sup-file, which is intrinsic to the program library. Fig. 7 (b), in its turn, shows the component icon that has been created.

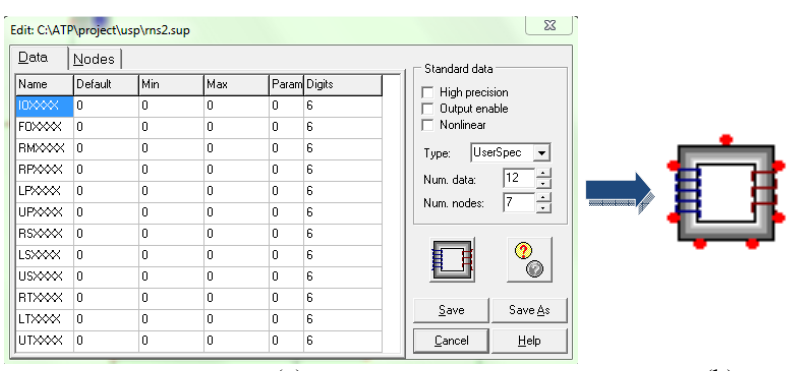

(a)

(b)

Fig. 7. Component created at the ATPDraw interface-SCR.sup.

Once a single column modeling has been developed, the others are then simply achieved by interconnecting the overall winding structures of the saturated reactor so as to achieve the required twin-tripler topology. This, as already mentioned, is formed by two cores with three independent magnetic columns. Each column is built up by two concentric windings, a principal winding having $(\mathrm{Np})$ turns and an auxiliary winding with $(\mathrm{Na})$ turns. The windings are connected in zigzag, with a star floating connection at the end. In Fig. 8, one can visualize the whole structure connections in accordance with the TPDraw needs. The three upper blocks correspond to the columns and windings of the first core, while the three lower components correspond to the elements of the second core. Further information about the procedures here summarized can be found in references [11] and [13].

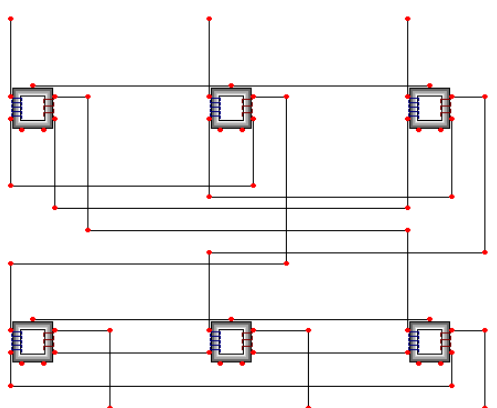

Fig. 8. Representation of the twin-tripler SCR in the ATPDraw simulator. 


\section{The Electrical Arrangement Used for Testing Purposes}

Fig. 9 is indicative of both computational and experimental arrangements that were utilized in the studies. It can be observed the presence of a supply source, a tap changer transformer to vary the saturated reactor applied voltage, and the tested equipment itself.

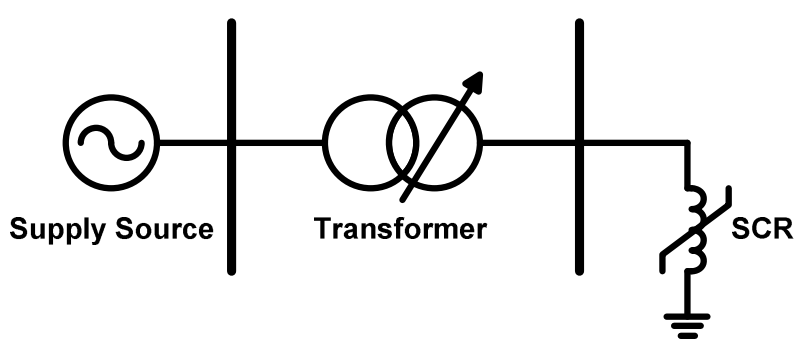

Fig. 9. Single-line diagram of the electrical system used for SCR computational and experimental tests.

As for the real installations where the (600kVAr-13.8kV) and (3 MVAr-34.5kV) prototypes were installed, Fig. 10 show the physical locations. Again, the variable voltages were produced by manually controlling a tap changer transformer that was released for the test purposes.

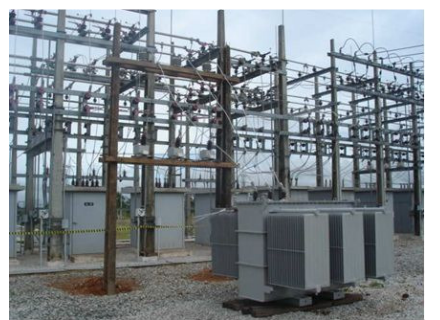

(a) SCR - (600 KVAr-13.8 kV)

Fig. 10. Stations where the real scale saturable reactors were installed.

\section{Computational Studies}

Although three saturated reactors have been used for the experimental evaluation, as for the theoretical investigations, five units were considered. Two of them (12 MVAr at $138 \mathrm{kV}$ and $25 \mathrm{MVAr}$ at $230 \mathrm{kV}$ ) have been hypothetically designed and utilized, so real prototype units were not constructed. The idea for such studies occurred by the need of examining the behavior of much larger equipment then the built up ones. In relation to the other three devices, a $7 \mathrm{kVAr}-220 \mathrm{~V}$, a $600 \mathrm{kVAr}-13.8$ $\mathrm{kV}$ and a $3 \mathrm{MVAr}-34.5 \mathrm{kV}$ real scale reactors have been constructed and made available for both computational and experimental performance evaluation. The Table 1 gives the main parameters and rated values for the mentioned SCR's. It must be understood that two voltage levels are cited. One is the rated value which corresponds to the system nominal one. The second voltage corresponds to the one that the reactor takes in the stated reactive power here referred. This voltage has been denoted by rated saturated value - Vsat.
Table I - SCR's Main Characteristics.

\begin{tabular}{|c|c|c|c|}
\hline $\begin{array}{c}\text { REACTIVE } \\
\text { POWER } \\
\text { [MVAr] }\end{array}$ & $\begin{array}{c}\text { RATED } \\
\text { VOLTAGE } \\
{[\mathrm{kV}]}\end{array}$ & $\begin{array}{c}\text { SATURATION } \\
\text { VOLTAGE (Vsat) } \\
{[\mathrm{kV}]}\end{array}$ & $\begin{array}{c}\text { RATED } \\
\text { CURRENT } \\
{[\mathrm{A}]}\end{array}$ \\
\hline 0.007 & 0.22 & 0.22 & 18.2 \\
\hline 0.6 & 13.8 & 13.9 & 24.3 \\
\hline 3 & 34.5 & 36 & 48.1 \\
\hline 12 & 138 & 138 & 50.2 \\
\hline 25 & 230 & 230 & 62.8 \\
\hline
\end{tabular}

Fig. 11 shows the relationship between the concatenated fluxes as a function of operating currents for the selected reactors, i.e., the $(\lambda \times$ i) curves provided by the ATP model focused in this paper. The procedure to obtain these results followed the steps previously described and were derived by aggregating the $\mathrm{BxH}$ nonlinear data sheet information to constructive parameters. It is worthwhile to notice that the curves highlight different values for the concatenated fluxes $(\lambda)$ when different equipment is used. The figures use logarithmic scale for the flux axis, and the individual results are in agreement with the physical expectances.

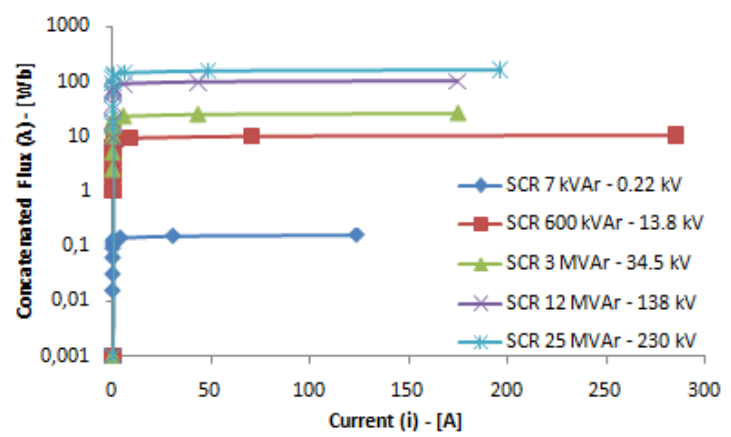

Fig. 11. Magntization curves of the analyzed reactors.

Following, operational studies were computationally carried out with rated saturated voltage and under voltage conditions. Then, the first investigation comprises the reactor performance with Vsat and the second one with $93 \%$ of this value. The latter represents a situation in which the equipment is estimated to absorb only a residual power of the system that should be, ideally, nil. For both operating conditions, the following variables were assessed: voltage applied to the reactor, reactive power, operating current and total harmonic current distortion (THDi). Table 2 summarizes the final performance associated to the five reactors in focus.

Table II - Results Obtained in Tests Carried out at ATP.

\begin{tabular}{|c|c|c|c|c|c|c|c|}
\hline \multirow{2}{*}{$\begin{array}{l}\text { SCR } \\
\text { MVAr }\end{array}$} & \multirow{2}{*}{$\begin{array}{c}\text { Rated } \\
\text { Voltage } \\
\mathrm{kV}\end{array}$} & \multirow{2}{*}{$\begin{array}{l}\text { Applied } \\
\text { Voltage }\end{array}$} & \multicolumn{2}{|c|}{$\begin{array}{c}\text { Reactive } \\
\text { Power }\end{array}$} & \multicolumn{2}{|c|}{$\begin{array}{c}\text { Absorbed } \\
\text { Current }\end{array}$} & \multirow{2}{*}{$\begin{array}{c}\text { THDi } \\
\%\end{array}$} \\
\hline & & & MVAr & $\%$ & A & $\%$ & \\
\hline \multirow{2}{*}{0.007} & \multirow[b]{2}{*}{0.22} & Vsat & 0.007 & 100.7 & 18.3 & 100.7 & 18.1 \\
\hline & & 0.93.Vsat & 0.002 & 21.3 & 4.2 & 21.3 & 28.3 \\
\hline \multirow{2}{*}{0.6} & \multirow{2}{*}{13.8} & Vsat & 0.600 & 102.3 & 24.9 & 102.4 & 24.0 \\
\hline & & 0.93.Vsat & 0.092 & 15.7 & 4.2 & 17.3 & 17.7 \\
\hline \multirow[t]{2}{*}{3} & \multirow{2}{*}{34.5} & Vsat & 3.137 & 104.6 & 50.3 & 104.6 & 23.7 \\
\hline & & 0.93.Vsat & 0.709 & 23.6 & 12.3 & 25.5 & 27.7 \\
\hline \multirow[b]{2}{*}{12} & \multirow{2}{*}{138} & Vsat & 12.11 & 100.9 & 50.9 & 101.4 & 24.9 \\
\hline & & 0.93 .Vsat & 2.716 & 22.6 & 13.1 & 25.9 & 23.8 \\
\hline \multirow{2}{*}{25} & \multirow{2}{*}{230} & Vsat & 25.61 & 102.4 & 64.8 & 103.3 & 23.0 \\
\hline & & 0.93.Vsat & 6.297 & 25.2 & 18.5 & 29.5 & 20.6 \\
\hline
\end{tabular}


For the rated saturated value of voltage condition, the reactive power and current were shown to be quite satisfactory, considering that they have reached $100 \%$ of the corresponding reactive power. Regarding the operation of the equipment with $93 \%$ of the above voltage level, the five units have demonstrated a reactive power consumption of about $20 \%$ or $30 \%$ of the full reactive power. This behavior is directly linked to the magnetic sheet utilized as well as the design parameters. By selecting other values, the non saturated voltage may yield to less reactive power driven by the reactor. As for the harmonic current distortion, these ranged between $17 \%$ and $28 \%$. These figures are in agreement with expected values.

\section{Experimental Studies}

Aiming at validating the proposed approach to represent the saturated reactor non linearity, the built up units were then tested with similar conditions to that previously stated. The individual experimental results, in terms of applied voltage and reactive power consumption by the $7 \mathrm{kVAr}-0.22 \mathrm{kV}, 600 \mathrm{kVAr}-13.8 \mathrm{kV}$ and $3 \mathrm{MVAr}-34.5 \mathrm{kV}$ units are given in Figs 12, 13 and 14, respectively. So as to provide means to compare the experimental and computational values, both, site results and the computational ones were plotted in the same figures.

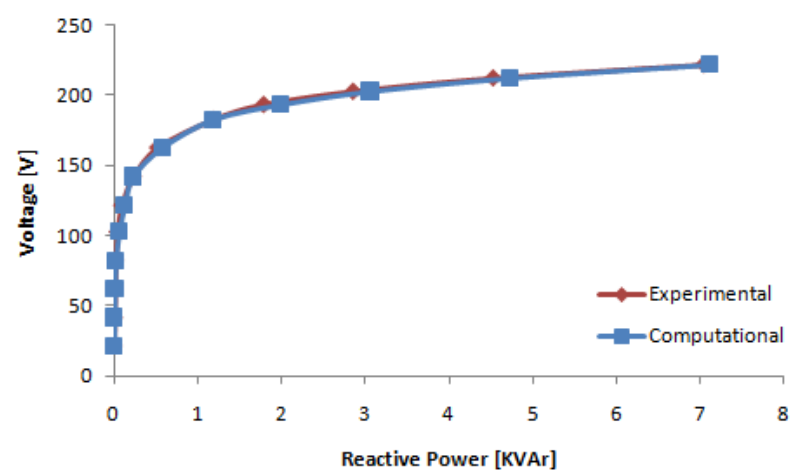

Fig. 12. Reactor applied voltage versus reactive power consumption-SCR 7 $\mathrm{kVAr}$ - experimental and computational results.

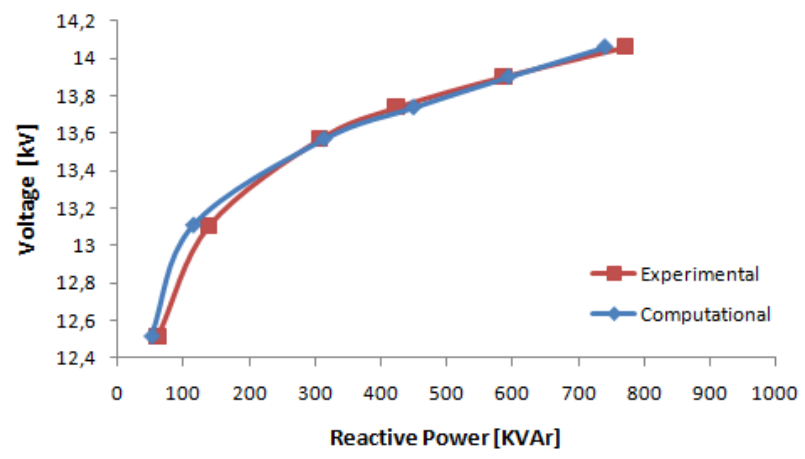

Fig. 13. Reactor applied voltage versus reactive power consumption- SCR $600 \mathrm{kVAr}$ - experimental and computational results.

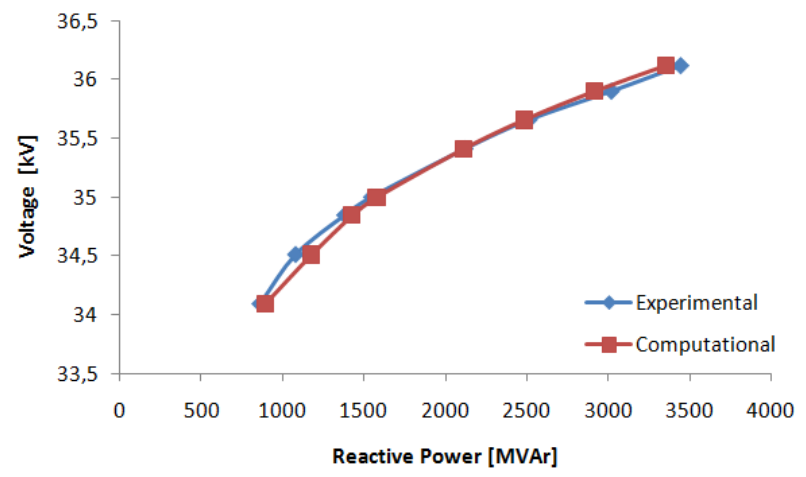

Fig. 14. Reactor applied voltage versus reactive power consumption- SCR $3 \mathrm{MVAr}$ - experimental and computational results.

On Figs. 12, 13 and 14, it can be promptly seen that the experimental and computational performance demonstrate a very good correlation. As a matter of fact, the major differences were found to be below $8 \%$.

As mentioned earlier, the nonlinear behavior of the SCR operation necessarily cause the production of harmonic currents by the saturated reactor. By recognizing this fact, once again the experimental and theoretical reactor current waveforms were compared. The results associated to the saturated voltage are illustrated by Figs. 15, 16 and 17. These express the current waveform and the corresponding harmonic spectrum for the three built up units. Also, it can be seen that only line A current is given as the others are quite similar.

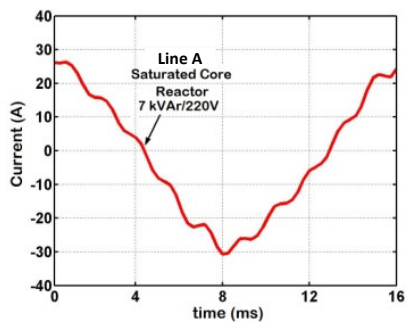

a) Current - experimental

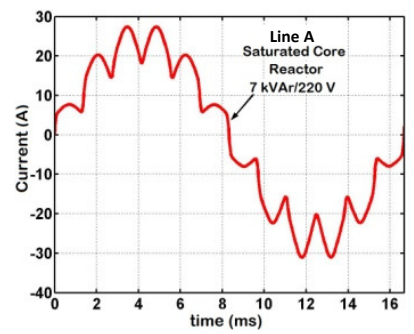

c) Current - computational

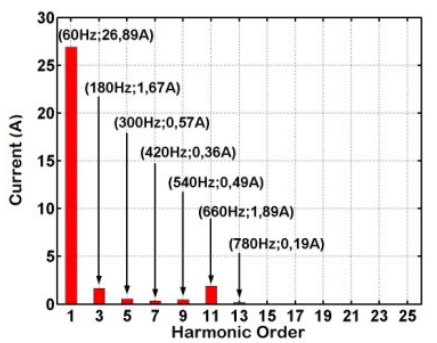

b) Harmonic espectrum - experimental

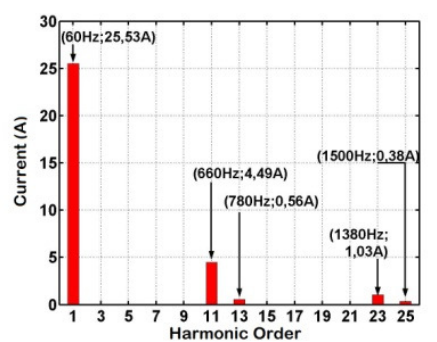

d) Harmonic espectrum - computational
Fig. 15 -SCR $7 \mathrm{kVAr}-0.22 \mathrm{kV}$.

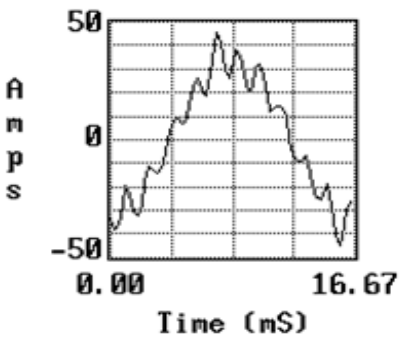

a) Current - experimental

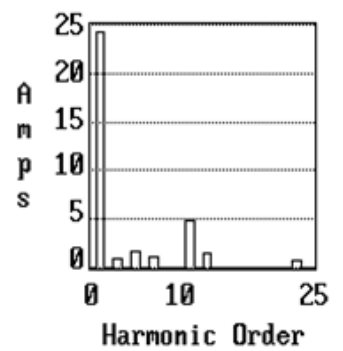

b) Harmonic espectrum - experimental 


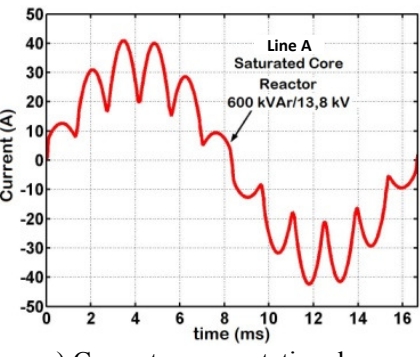

c) Current - computational

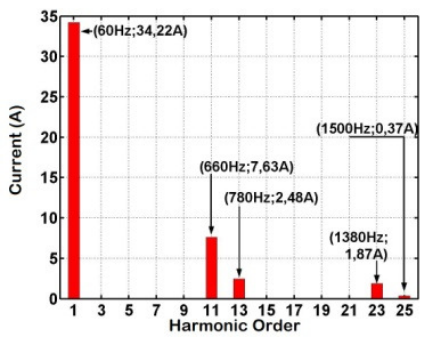

d) Harmonic espectrum - computational
Fig. 16 - SCR $600 \mathrm{kVAr}-13.8 \mathrm{kV}$.

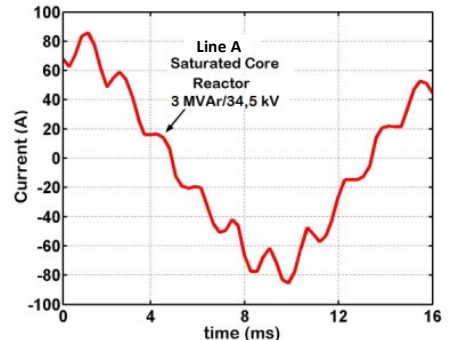

a) Current - experimental

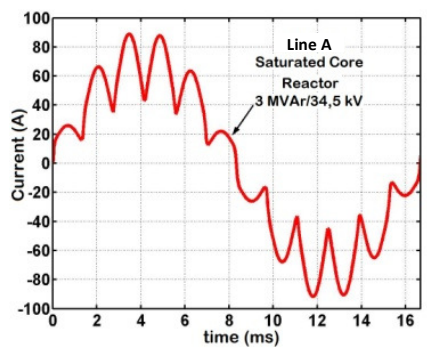

c) Current - computational

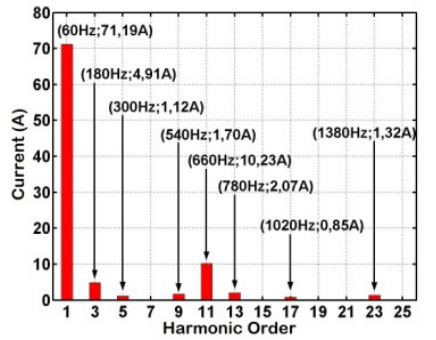

b) Harmonic espectrum - experimental

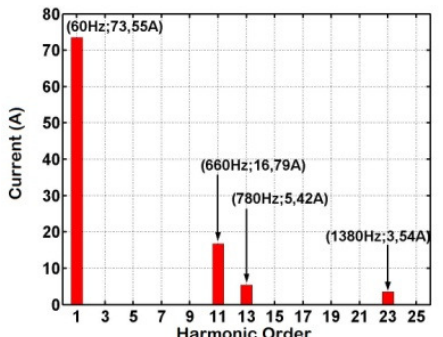

d) Harmonic Espectrum - computational
Fig. 17 - SCR 3 MVAr - 34.5 kV.

Again, a clear agreement between computational results and those extracted from experimental tests can be promptly seen. In addition, the current waveforms do reflect the twin-triple type of saturated reactor where the intrinsic cancelation of the $5^{\text {th }}, 7^{\text {th }}$ and other components can be noticed. As a matter of fact, only the harmonic orders defined by the expression $n=2 k \pm 1$ were found.

\section{Conclusion}

This paper has been dedicated to the establishment of a systematic procedure to obtain the magnetization curve to feed the saturated reactor in the ATPDraw platform. The main idea is to use a combination of construction information and the $\mathrm{BxH}$ relationship associated to the type of magnetic material utilized for the equipment manufacture. Once the approach was described, the nonlinear dependance obtained between the concatenated flux and current was inserted in the ATP program. This allows for transient, dynamic and steady state studies of saturated reactor with different supply voltage conditions. Using three different prototypes data, investigations have been performed to obtain the final reactive power versus voltage behavior, as well as current wave forms. By comparing theorectical results to experimental ones, it was possible to conclude they are in close agreement.

Therefore, as for steady state operating conditions, it has been demonstrated that the methodology here presented was shown to be quite appropriate to the establised purposes.

\section{Acknowledgement}

The authors express their acknowledgements to CNPq, CAPES, and FAPEMIG by their financial support for research and postgraduate program of FEELT-UFU.

\section{References}

[1] H. J. Thanawala, W. O. Kelham, A. M. Crawshaw, "Static Compensator Using Thyristor Control With Saturated Reators and With Low Reactance Linear Reactors", IEE Conference on Thyristor and Variable Static Equipment for $A C$ and $D C$ Transmission, London, 1981.

[2] J. D. Ainsworth, E. Friedlander, R. Yacamini, "Application of Saturated Reactor to AC Voltage Stabilization for HVDC Transmission and Other Large Convertors", IEEE Pas Summer Meeting and EHV/UHV Conference, Vancouver, Jul. 1973.

[3] E. Friedlander, "Principle and Analysis of a Strabilized Phase Multiplier Type of Magnetic Frequency Convertor", Electrical Energy, vol. I, pp. 55-66, Oct. 1956.

[4] E. Friedlander and K. M. Jones, "Saturated reactors for Long Distance Bulk Power Lines", $27^{\text {th }}$ Electrical Review, pp 940 - 943, Jun. 1969.

[5] C. B. Cooper and D. J. Young, "Saturated Reactor and Compensator for Stabilizing Voltage at Load and Generation Points", IEE International Conference on HD and/or AC Power Transmission, London, Nov. 1973.

[6] A. B. Vasconcellos, "Modeling, design and construction of saturated core reactor static compensator focusing power quality requirements" - $\mathrm{PhD}$ thesis - Federal University of Uberlandia Brazil - 2004

[7] J. M. Pacheco, "Determinação dos Parâmetros de Compensadores Estáticos de Reativos e Estratégia para o Projeto Otimizado de Reatores Saturados", Tese de Doutorado - Universidade Federal de Uberlândia, Uberlândia-MG, Brasil, Set. 2008.

[8] J. C. Oliveira, A. B. Vasconcellos, R. Apolônio, "Saturated Core Reactor Static Compensator: Computational versus Experimental Performance Analysis", $11^{\circ}$ International Conference on Harmonics and Quality of Power (ICHQP), New York, Sep. 2004.

[9] J. C. Oliveira, A. B. Vasconcellos, R. Apolônio, "A Strategy for Voltage Regulation in Eolic Systems", $11^{\circ}$ International Conference on Harmonics and Quality of Power (ICHQP), New York, Sep. 2004.

[10] J. C. Oliveira, A. B. Vasconcellos, R. Apolônio; "Saturated Core Reactor Static Compensator: Computational Analysis Versus Experimental" (in Portuguese), XV CBA, Gramado-RS, Brazil, September/2003.

[11] J. A. F. Barbosa Jr., J. C. Oliveira, F. P. Santilio, I. N. Gondim, A. B. Vasconcellos, J. M. Pacheco, "A Computational ATP Model and Validation to Represent Saturated Core Reactors", $9^{\text {th }}$ IEEE/IAS International Conference on Industry Applications (IX Induscon), São Paulo-SP, Nov. 2010.

[12] A. Martignoni, "Transformadores", $8^{\text {a }}$ Ed, Editora Globo, São Paulo-SP, 1991.

[13] Alternative Transient Program (ATP), Rule Book, Jul. 1987. 